\title{
Prophylactic use of tranexamic acid to reduces blood loss and transfusion requirements in caesarean section
}

\author{
Urmila Sunda*, Priyanka Bhadana
}

Department of Obstetrics and Gynecology, ABVIMS and RML Hospital, New Delhi, India

Received: 11 May 2020

Accepted: 04 June 2020

*Correspondence:

Dr. Urmila Sunda,

E-mail: drurmilasundagwalior@gmail.com

Copyright: (C) the author(s), publisher and licensee Medip Academy. This is an open-access article distributed under the terms of the Creative Commons Attribution Non-Commercial License, which permits unrestricted non-commercial use, distribution, and reproduction in any medium, provided the original work is properly cited.

\begin{abstract}
Background: Postpartum haemorrhage (PPH) is most dreaded complication which occurs worldwide, more prevalent in developing countries after both vaginal and caesarean delivery. Prophylactic administration of a uterotonics immediately after delivery is the only procedure that has been proved to reduce rates of postpartum haemorrhage. Tranexamic acid, an antifibrinolytic is recommended by WHO for management of PPH, its role to reduce blood loss in caesarean section as a prophylactic agent is not well studied.

Methods: This study was conducted in a tertiary care hospital at New Delhi total 100 pregnant women with age $\geq 18$ and <35 years and singleton alive fetus who underwent caesarean section were included for this study. Study population was divided in two group. Women assigned to the study group received $1 \mathrm{gm}$ tranexamic acid slowly intravenously over 10 minutes after delivery of the baby as per existing unit protocol. Those women who received tranexamic acid was compared with other group who did not received tranexamic acid. The primary outcomes were mean blood loss (ml) and mean fall in hemoglobin level within 48 hours after surgery.

Results: Amount of blood loss was significantly low (mean $369 \mathrm{ml}$ ) in tranexamic acid group as compared to control group $(488 \mathrm{ml}$ ), the difference was statistically significant ( $\mathrm{p}$ value 0.001 ). Mean fall in haemoglobin level was also low $(1.17 \mathrm{mg} / \mathrm{dl})$ in group who received tranexamic acid as compared to control group $(1.87 \mathrm{mg} / \mathrm{dl})$, the difference was statistically significant ( $\mathrm{p}$ value 0.001 ). Postpartum hemorrhage (blood loss more than $1000 \mathrm{ml}$ ) was observed in 1 patient in control group and no case of PPH was observed in study group.

Conclusions: Tranexamic acid administration prior to caesarean section was effective in reducing the blood loss intra and postoperative period, without any immediate maternal and neonatal adverse events as well as reduces the need of blood transfusion.
\end{abstract}

Keywords: Caesarean section, Postpartum haemorrhage, Tranexamic acid

\section{INTRODUCTION}

Postpartum haemorrhage (PPH) is most dreaded complication which occurs worldwide, more prevalent in developing countries after both vaginal and caesarean delivery. Despite appropriate interventions to prevent and treat, postpartum haemorrhage remains the leading individual cause of death worldwide. It accounts $19.7 \%$ of all maternal deaths worldwide. ${ }^{1}$ It is the most common maternal morbidity even in highly resourced countries and is increasing in incidence. ${ }^{2}$ Incidence of PPH varies from $3-15 \%$ of deliveries and around $1-2 \%$ cases progress to severe form and endangers mother's life and increases risk of additional surgical procedures, blood transfusion, infertility and ICU admission.

PPH is defined as loss of blood $500 \mathrm{ml}$ or more in vaginal delivery and $1000 \mathrm{ml}$ or more in caesarean delivery within 24 hours of delivery. ${ }^{3}$ Another definition of PPH is that blood loss sufficient to cause hemodynamic instability and requiring transfusion of blood product and $10 \%$ drop in haematocrit. It is aphoristic that occurrence 
of $\mathrm{PPH}$ is unpredictable however risk factor may be associated with it. It is studied that the main cause of PPH is a tonicity followed by trauma in various forms, retained tissue and coagulopathy. ${ }^{4}$

Prophylactic administration of a uterotonics immediately after delivery is the only procedure that has been proved to reduce rates of postpartum haemorrhage. ${ }^{5}$ Tranexamic acid, an antifibrinolytic acts via blocking the lysine binding site of the plasminogen and plasmin molecule thus inhibit plasminogen activation and fibrinolysis. ${ }^{6}$ The rational of its use in puerperium to prevent blood loss is supported by the physiological alteration in homeostasis occurs in puerperium. Puerperium is a state of hypercoagulability and hypo fibrinolysis which alleviates risk of PPH at delivery. ${ }^{7}$

WHO describes haemorrhage as one of the biggest cause of obstetrics mortality globally representing around 27 percent of all obstetrics related death. The increased use of tranexamic acid is based on the finding of various studies including TRAAP trial, woman study, CRASH 2 trial. $^{8-10}$ However, analysis of concluded studies is challenging due to significant heterogenicity between study in terms of definition of PPH measurement tool for blood loss and patient inclusion.

Recently WHO has recommended early use of intravenous tranexamic acid within three hours of birth in addition to routine care for women with clinically diagnosed PPH regardless of the cause of bleeding following vaginal birth or caesarean section. ${ }^{11}$

\section{METHODS}

This study was conducted in a tertiary care hospital at New Delhi during the period from January 2019 to December 2019. All pregnant women with age $\geq 18$ and $<35$ years and singleton alive fetus who underwent caesarean section were included for this study.

Women with pregnancy related complication like severe preeclampsia, multiple pregnancy, polyhydramnios, antepartum hemorrhage and severe anemia ( $\mathrm{Hb}<7$ $\mathrm{gm} / \mathrm{dl}$ ), known case of coagulation disorders severe medical and surgical complications involving the heart, liver, kidney and brain, history of venous thromboembolism, sensitivity to tranexamic acid and patients taking anticoagulant were excluded from study. Study population was divided in two group. Women assigned to the study group received tranexamic acid as per existing unit protocol. Tranexamic acid $1 \mathrm{gm}$, given slowly intravenously over 10 minutes after delivery of the baby. TA injection was prepared by diluting $1 \mathrm{gm}(10 \mathrm{ml})$ TA with $20 \mathrm{ml}$ of $5 \%$ glucose. Those women who received tranexamic acid was compared with other group who did not received tranexamic acid (Figure 1).

Heart rate, respiratory rate and blood pressure were measured before and after surgery. Haemoglobin and hematocrit level were measured before caesarean section and two days after surgery. Prophylactic oxytocin was used in both groups. Intraoperative blood loss was measured using visual analogue scale and blood measured in suction bottles. The primary outcomes were mean blood loss (ml) and mean fall in hemoglobin level within 48 hours after surgery. Secondary outcomes included the incidence of postpartum hemorrhage, use of additional uterotonics, use of additional surgical intervention to control PPH, the incidence of side effects such as nausea, vomiting, headache, skin reaction and thromboembolic events were recorded.

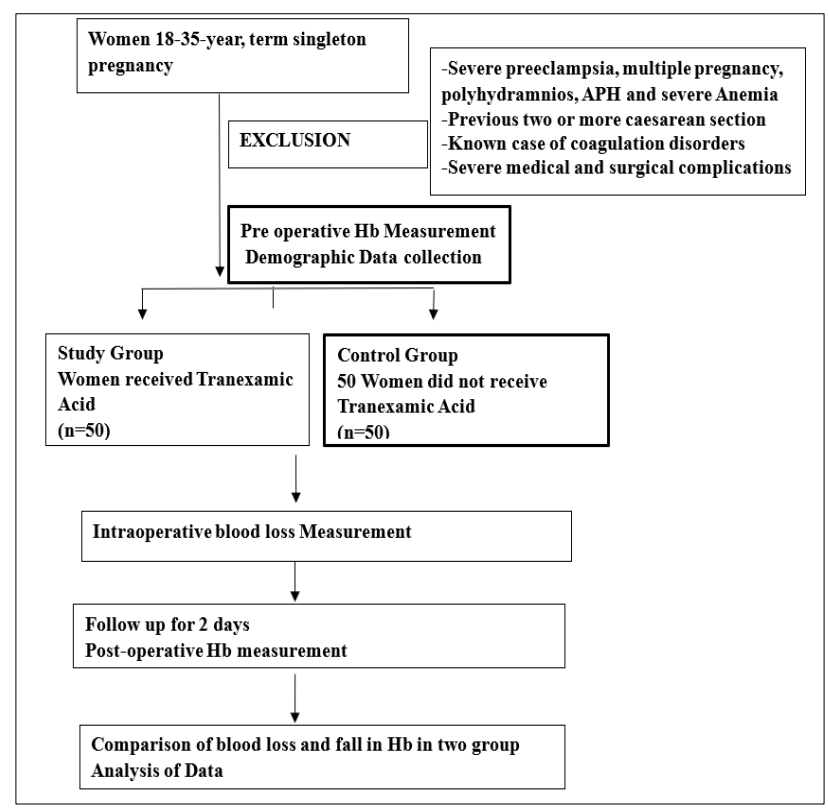

Figure 1: Study flow chart.

\section{Statistical analysis}

Data were analysed into SPSS software version 20 (SPSS Inc., Chicago, IL). Categorical data were compared using Chi square test, RR and $95 \%$ confidence interval. For continuous data, the means were compared using student t-test.

\section{RESULTS}

Demographic profile including maternal age, parity and gestational age were comparable in both groups and no significant difference were observed (Table 1).

Mean gestation in both groups was near term 37 weeks. Most common indication of caesarean section was fetal distress (38\% in study group and 34\% in control group) followed by breech presentation and previous caesarean section (Figure 2, 3).

Mean haemoglobin level before C-section was comparable in both groups. Amount of blood loss was significantly low (mean $369 \mathrm{ml}$ ) in tranexamic acid group as compared to control group $(488 \mathrm{ml})$, the difference 
was statistically significant ( $\mathrm{p}$ value 0.001 ). Mean fall in haemoglobin level was also low $(1.17 \mathrm{mg} / \mathrm{dl})$ in group who received tranexamic acid as compared to control group $(1.87 \mathrm{mg} / \mathrm{dl})$, the difference was statistically significant ( $\mathrm{p}$ value 0.001 ) (Table 2).

Table 1: Demographic profile.

\begin{tabular}{|llll|}
\hline & Maternal age $($ Mean \pm SD) & Gravida $($ Mean \pm SD $)$ & Gestation $($ Mean \pm S D) \\
\hline Study group & $27.16 \pm 4.11$ & $1.64 \pm 0.92$ & $37.11 \pm 1.58$ \\
\hline Control group & $26.94 \pm 2.59$ & $1.66 \pm 0.87$ & $36.98 \pm 1.84$ \\
\hline
\end{tabular}

Table 2: Comparison of mean hemoglobin before and after caesarean section.

\begin{tabular}{|lllll|}
\hline & $\begin{array}{l}\text { Haemoglobin } \\
\text { Before caesarean } \\
\text { section (Mean } \pm \text { SD) }\end{array}$ & $\begin{array}{l}\text { Haemoglobin } \\
\text { After caesarean section } \\
(\text { Mean } \pm \text { SD) }\end{array}$ & $\begin{array}{l}\text { Fall in hemoglobin } \\
\text { Mean } \pm \text { SD }\end{array}$ & $\begin{array}{l}\text { Blood loss }(\mathrm{ml}) \\
\text { Mean } \pm \text { SD }\end{array}$ \\
\hline Study group & $11.07 \pm 1.19$ & $9.89 \pm 1.17$ & $1.17 \pm 0.23$ & $369.40 \pm 63.5$ \\
\hline Control group & $11.11 \pm 1.12$ & $9.24 \pm 1.01$ & $1.87 \pm 0.52$ & $488 \pm 126.6$ \\
\hline p value & 0.84 & 0.004 & 0.001 & 0.001 \\
\hline
\end{tabular}

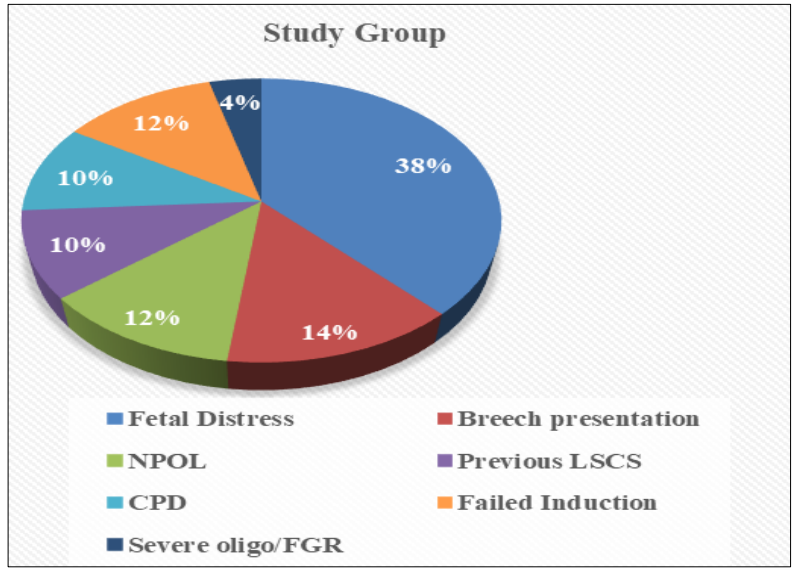

Figure 2: Distribution of case according to indication of caesarean section in study group.

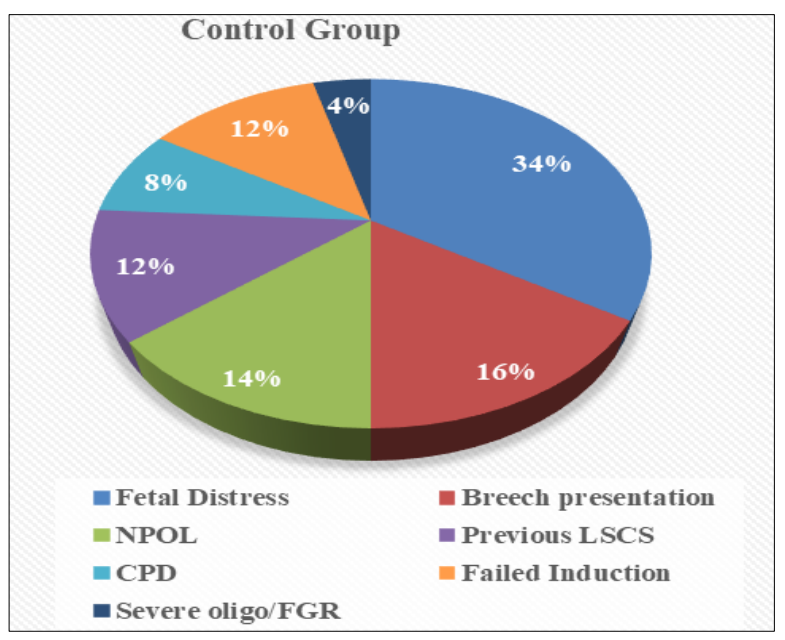

Figure 3: Distribution of case according to indication of caesarean section in control group.
Table 3: Requirement of maternal blood transfusions.

\begin{tabular}{|llll|}
\hline Blood & $\begin{array}{l}\text { Study group } \\
\text { transfusions }\end{array}$ & $\begin{array}{l}\text { Control group } \\
\mathbf{N}(\%)\end{array}$ & $\begin{array}{l}\text { p } \\
\text { v }(\%)\end{array}$ \\
\hline Yes & $2(4 \%)$ & $4(8 \%)$ & $<0.05$ \\
\hline No & $48(96 \%)$ & $46(92 \%)$ & \\
\hline
\end{tabular}

Table 4: Comparison of vital parameters.

\begin{tabular}{|c|c|c|c|}
\hline Parameters & $\begin{array}{l}\text { Study group } \\
\text { (Mean) }\end{array}$ & $\begin{array}{l}\text { Control } \\
\text { group (Mean) }\end{array}$ & $\begin{array}{l}\mathbf{p} \\
\text { value }\end{array}$ \\
\hline \multicolumn{4}{|l|}{ Pulse rate } \\
\hline Preop & 81.3 & 81.6 & \multirow{3}{*}{$<0.01$} \\
\hline Postop & 84.6 & 88.4 & \\
\hline Difference & +3.3 & +6.8 & \\
\hline \multicolumn{4}{|l|}{ Systolic BP } \\
\hline Preop & 110.8 & 112.4 & \multirow{3}{*}{0.3} \\
\hline Postop & 108.6 & 109.8 & \\
\hline Difference & -2.2 & -2.6 & \\
\hline \multicolumn{4}{|l|}{ Diastolic BP } \\
\hline Preop & 78.6 & 78.8 & \multirow{3}{*}{$<0.001$} \\
\hline Postop & 78.2 & 76.2 & \\
\hline Difference & -0.4 & -2.6 & \\
\hline
\end{tabular}

There was statistically significant difference were observed in both groups in terms of need of maternal blood transfusion. Although the mean blood loss in each group was below $500 \mathrm{ml}$ but the requirement of blood transfusion was low $2(4 \%)$ in study group as compared to $4(8 \%)$ control group (Table 3). Postpartum hemorrhage (blood loss more than $1000 \mathrm{ml}$ ) was observed in 1 patient in control group and no case of $\mathrm{PPH}$ was observed in study group. Neonatal outcomes and immediate maternal and neonatal complications were comparable between both groups and no statistical difference was noted in both groups. 
Vital parameters including pulse rate, BP were compared in preop and post-operative period and statistically significant changes were noted in both parameters in both groups which were directly related to amount of blood loss in intraoperative and immediate postoperative period (Table 4).

\section{DISCUSSION}

The present study was conducted at a tertiary centre in Delhi. Study institute had adequate antenatal care and it is also reflected in demographic profile of the enrolled patient. Anemia in pregnancy prematurity and early pregnancy is common in Indian population. Most of the patients in this study were near term gestation, age between 20-30 year, mean pre-operative $\mathrm{Hb}$ level was above $11 \mathrm{mg} / \mathrm{dl}$ in both groups, although patient with severe anemia were excluded in this study.

Obstetric haemorrhage is a most dreadful complication in pregnancy and worst nightmare for an obstetrician, as prevention is always better than cure hence role of tranexamic acid in prevention of blood loss during and after caesarean section was observed in this study. Anemic women may deteriorate even with small amount of blood loss even before reaching the cut off for diagnosis of PPH during CS (blood loss of $1000 \mathrm{~mL}$ ). Improving antenatal care, treating anemia before delivery and measures for prevention of blood loss in vaginal delivery and CS, are important in decreasing maternal deaths.

TXA is a pro-hemostatic agent which facilitates the hemostatic process by its ability of sustaining a clot by inhibiting fibrinolytic activity. there is release of coagulant factors and rapid degradation of fibrinogen and fibrin during process of delivery owing to vascular injury. ${ }^{12}$ These processes increase fibrinolysis which can last for several hours postpartum. Extensive tissue injury caused by the CS further increases fibrinolysis and increases bleeding. ${ }^{13}$ Therapeutic levels of TXA are maintained for 8 hours after CS which covers the period of hyperfibrinolysis.

This explains the role of TXA in reducing blood loss during and after surgery. Previous studies also suggest reduce blood loss with tranexamic acid uses. Mean blood loss during surgery ranged from 250 to $500 \mathrm{~mL}$ in the study group and from 329 to $710 \mathrm{~mL}$ in the control groups by various authors. ${ }^{14-17}$

In this study changes in vital parameters are statistically significant in study group after use of tranexamic acid as compared to control group. Mean post-operative increase in pulse rate was $3.3 / \mathrm{min}$ in study group and $6.8 / \mathrm{min}$ in control group. The mean fall in SBP was $2.2 \mathrm{~mm} \mathrm{Hg}$ in study group as compared to 2.6 in control group. Mean fall in DBP was $0.4 \mathrm{mmHg}$ in study group and $2.6 \mathrm{mmHg}$ in control group. Changes in vital parameters are directly related to amount of blood loss. In similar study conducted by Novikova et al. ${ }^{18}$

This study also concluded a significant fall in mean haemoglobin level postoperatively in control group as compared to study group (1.17 versus $1.87 \mathrm{mg} / \mathrm{dl})$ as well as significant amount of blood loss intraoperatively and postoperatively in control group (488 ml versus 369.4 $\mathrm{ml}$ ). The difference in the mean blood loss between study and control group also reflected in the fall in mean $\mathrm{Hb} \%$ after surgery observed in the two groups which was significant statistically.

This study also noted the requirement of blood transfusion in both groups and concluded that only 2 patients in study group compared to 4 case in control group needed blood transfusion, this observation is directly related to amount of blood loss during and after cs in both groups. TXA carries a risk of thrombosis specially in those with a previous history of thrombosis but the current literature shows no significant increases in the incidence of thromboembolic events. ${ }^{19}$

Immediate maternal and neonatal complication also assessed in this study and observed that there are no statistically significant side effects were noted in both groups. However long-term effects of the drug on the mother as well as her baby are not well known. The issue of safety along with other concerns will be solved by a multi-centred, double-blind, randomized controlled trial which plans to involve large sample size. ${ }^{19}$ Cochrane review also shows decreased blood loss with the use of TXA in caesarean section. In a recent meta-analysis, the mean total blood loss during and after CS was significantly low in TXA group than in control group having a mean difference of $141.61 \mathrm{~mL}(\mathrm{p}<0.01) .{ }^{20}$

TXA is cheap, easily available drug and it does not require cold chain for storage. It can be useful in prevention of maternal mortality and morbidity in resource limited countries where healthcare facilities are sparse.

\section{CONCLUSION}

Tranexamic acid-an antifibrinolytic agent, administration prior to caesarean section was effective in reducing the blood loss intra and postoperative period, thus reduces the incidence of PPH without any immediate maternal and neonatal adverse events as well as reduces the need of blood transfusion and its related complications. Although long term consequences of use of tranexamic acid yet to be studied.

\section{ACKNOWLEDGMENTS}

Authors would like to thank to the residents, nursing staff of the department of obstetrics and gynecology and department of anesthesia for their help in collecting and storing the data. 
Funding: No funding sources

Conflict of interest: None declared

Ethical approval: The study was approved by the Institutional Ethics Committee

\section{REFERENCES}

1. Say L, Chou D, Gemmill A, Tunçalp Ö, Moller AB, Daniels J, et al. Global causes of maternal death: a WHO systematic analysis. Lancet Glob Health. 2014;2(6):e323-333.

2. Knight M, Callaghan WM, Berg C, Alexander S, Bouvier-Colle MH, Ford JB, et al. Trends in postpartum hemorrhage in high resource countries: a review and recommendations from the International Postpartum Hemorrhage Collaborative Group. BMC Preg Childbirth. 2009;9:55.

3. WHO recommendations for the prevention and treatment of postpartum haemorrhage. World Health Organization; Available http://www.who.int/reproductivehealth/publications/mat ernal_perinatal_health/9789241548502/en/. Accessed on $12^{\text {th }}$ April 2020.

4. Sebghati M, Chandraharan E. An update on the risk factors for and management of obstetric haemorrhage. Womens Health. 2017;13(2):34-40.

5. Begley CM, Gyte GML, Devane D, McGuire W, Weeks A. Active versus expectant management for women in the third stage of labour. Cochrane Database Syst Rev. 2011;(11):CD007412.

6. Wu G, Mazzitelli BA, Quek AJ, Veldman MJ, Conroy PJ, Caradoc-Davies TT, et al. Tranexamic acid is an active site inhibitor of urokinase plasminogen activator. Blood Adv. 2019;3(5):729-33.

7. Moiz B. A review of hemostasis in normal pregnancy and puerperium. Nat J Health Sci. 2017;2(3):123-7.

8. Sentilhes L, Winer N, Azria E, Sénat MV, Le Ray C, Vardon D, et al. Tranexamic acid for the prevention of blood loss after vaginal delivery. $\mathrm{N}$ Engl $\mathrm{J}$ Med. 2018;379(8):731-42.

9. Shakur H, Elbourne D, Gülmezoglu M, Alfirevic Z, Ronsmans C, Allen E, et al. The woman trial (World maternal antifibrinolytic trial): tranexamic acid for the treatment of postpartum haemorrhage: an international randomised, double blind placebo-controlled trial. Trials. 2010;11:40.

10. Roberts I, Shakur H, Coats T, Hunt B, Balogun E, Barnetson L, et al. The CRASH-2 trial: a randomised controlled trial and economic evaluation of the effects of tranexamic acid on death, vascular occlusive events and transfusion requirement in bleeding trauma patients. Health Technol Assess Winch Engl. 2013;17(10):1-79.

11. WHO recommendation on tranexamic acid for the treatment of postpartum haemorrhage. World Health Organization. Available at: http://www.who.int/reproductivehealth/publications/tra nexamic-acid-pphtreatment/en. Accessed on $12^{\text {th }}$ April 2020.

12. Lakshmi SD, Abraham R. Role of prophylactic tranexamic acid in reducing blood loss during elective caesarean section: a randomized controlled study. J Clin Diagn Res. 2016;10(12):QC17-21.

13. Levy JH, Dutton RP, Hemphill JC, Shander A, Cooper $\mathrm{D}$, Paidas MJ, et al. Multidisciplinary approach to the challenge of hemostasis. Anesth Analg. 2010;110(2):354-64.

14. Gungorduk K, Yildırım G, Asıcioglu O, Gungorduk OC, Sudolmus S, Ark C. Efficacy of intravenous tranexamic acid in reducing blood loss after elective caesarean section: a prospective, randomized, doubleblind, placebo-controlled study. Am J Perinatol. 2011;28:233-40.

15. Movafegh A, Eslamian L, Dorabadi A. Effect of intravenous tranexamic acid administration on blood loss during and after caesarean delivery. Int J Gynecol Obstet. 2011;115:224-6.

16. Shahid A, Khan A. Tranexamic acid in decreasing blood loss during and after caesarean section. J Coll Physicians Surg Pak. 2013;23:459-62.

17. Nath J. A study on use of tranexamic acid in reducing blood loss during lower segment caesarean section. Int $\mathbf{J}$ Sci Res. 2015;4:1236-8.

18. Novikova N, Hofmeyr GJ, Cluver C. Tranexamic acid for preventing postpartum haemorrhage. Cochrane Database Syst Rev. 2015;(6):CD007872.

19. Sentilhes L, Daniel V, Darsonval A, Deruelle P, Vardon D, Perrotin F, et al. Study protocol. TRAAPTRAnexamic acid for preventing postpartum hemorrhage after vaginal delivery: a multicentre randomized, double-blind, placebo-controlled trial. BMC Preg Childbirth. 2015;15(1):135.

20. Wang HY, Hong SK, Duan Y, Yin HM. Tranexamic acid and blood loss during and after caesarean section: a meta-analysis. J Perinatol. 2015;35(10):818-25.

Cite this article as: Sunda U, Bhadana P.

Prophylactic use of tranexamic acid to reduces blood loss and transfusion requirements in caesarean section. Int J Reprod Contracept Obstet Gynecol 2020;9:2987-91. 